\title{
Over-the-scope clip in peptic ulcer bleeding: clinical success in primary and secondary treatment and factors associated with treatment failure
}

\section{(ㄷ)(우우}

\author{
Authors \\ Johannes Stueckle², Alexander Meier², Helmut Messmann¹ \\ Institutions \\ 1 University Hospital Augsburg, Department of Internal \\ Medicine III, Augsburg, Germany \\ 2 Klinikum Dritter Orden, Department of Internal \\ Medicine I, Munich, Germany \\ 3 Chair of Epidemiology of the LMU Munich at UNIKA-T, \\ Augsburg, Germany
}

Stefan Gölder ${ }^{1}$, Lukas Neuhas², Denis Freuer ${ }^{3}$, Andreas Probst ${ }^{1}$, Alanna Ebigbo ${ }^{1}$, Georg Braun¹, Juliane Brueckner ${ }^{2}$,

submitted 9.11.2018

accepted after revision 25.3.2019

\author{
Bibliography \\ DOI https://doi.org/10.1055/a-0898-3357 | \\ Endoscopy International Open 2019; 07: E846-E854 \\ (c) Georg Thieme Verlag KG Stuttgart · New York \\ eISSN 2196-9736
}

\section{Corresponding author}

Dr. Stefan Karl Gölder, University Hospital Augsburg -

Department of Internal Medicine III, Stenglinstraße 2,

Augsburg 86156, Germany

Fax: +498214003331

stefan.goelder@uk-augsburg.de
ABSTRACT

Background and study aims It is unclear if the clinical success rate of the over-the-scope-clip (OTSC) in peptic ulcer bleeding (PUB) is comparable when it is used in the firstor in the second-line of treatment.

Patients and methods Data on endoscopic treatment (first- vs. second-line) in PUB with OTSC and clinical data were analyzed. The primary outcome was the clinical success of hemostasis, defined as the absence of recurrent bleeding or further intervention. Secondary outcomes were factors associated with OTSC failure.

Results From April 2014 to March 2018, 100 patients (age 72 [20-98] y, female $36 \%$ ) with PUB in the stomach or the duodenum were treated endoscopically with the OTSC. The OTSC was used as a first-line procedure (primary-OTSC) in 66 pts. Successful hemostasis could be achieved in $90.9 \%$. After failure of an initial endoscopic treatment, 34 patients were treated with the OTSC (secondary-OTSC) and the treatment was successful in $94.1 \%$. Recurrent bleeding occurred in $\mathrm{n}=10$ for primary-OTSC (16.7\%) and in $\mathrm{n}=7 \mathrm{pts}$ in the secondary-OTSC $(21.9 \%)(P=0.81)$. Clinical success in the primary-OTSC was $75.8 \%$ and $73.5 \%$ in the secondaryOTSC respectively.

Conclusions The OTSC has a high rate of initial bleeding control in first- and second line treatment of PUB. OTSC failure occurs more often in the duodenum than in the stomach and results in longer intensive care unit stay, higher amount of transfusions, and a higher reimbursement per case.

\section{Introduction}

Acute upper gastrointestinal hemorrhage remains one of the most common emergencies in internal medicine. The incidence rate of upper gastrointestinal bleeding is between 40 and 150 cases per 100.000 [1,2]. Peptic ulcer bleeding (PUB) is still the most common bleeding source and responsible for $40 \%$ to $50 \%$ of all acute upper gastrointestinal bleeding episodes [1,3]. Internationally accepted treatment standards and guidelines recommend early use of endoscopic therapy and proton pump in- hibitors [ $4-6$ ]. However, about $8 \%$ to $15 \%$ of all patients have persistent or recurrent bleeding and the mortality rate for PUB still remains between $10 \%$ to $14 \%[3,7]$.

The over-the-scope-clip (OTSC) has been introduced as a new treatment option and in a recent prospective randomized study, Schmidt et al showed that use of the device is superior to conventional endoscopic treatment in recurrent PUB (secondary-OTSC) [8]. Until now it was unclear if the OTSC could be as helpful in first-line treatment of PUB (primary-OTSC). In our study, we compared primary-OTSC with secondary-OTSC in 
- Table 1 Baseline Characteristics of $n=100$ patients with peptic gastric or duodenal ulcer bleeding (PUB) and treatment with the overthe-scope cClip (OTSC).

\begin{tabular}{|c|c|}
\hline & Median (IQR), N, (\%) \\
\hline $\mathrm{Age}^{1}$ & $76(62.75 ; 83)$ \\
\hline Patient clinical complexity level (PCCL) & $3(1.75 ; 4)$ \\
\hline \multicolumn{2}{|l|}{ Gender } \\
\hline - male & 64 \\
\hline - female & 36 \\
\hline Outpatient bleeder & 57 \\
\hline Inpatient bleeder & 43 \\
\hline \multicolumn{2}{|l|}{ Anticoagulation } \\
\hline - None & 56 \\
\hline - ASS mono & 8 \\
\hline - NOAK & 8 \\
\hline - combinations & 28 \\
\hline \multicolumn{2}{|l|}{ NSAR } \\
\hline - No & 49 \\
\hline - Yes & 17 \\
\hline " Unclear & 2 \\
\hline RockallScore & $7(6 ; 8)$ \\
\hline Glasgow Blatchford Score (GBS) & $16(14 ; 17)$ \\
\hline Ulcer size (mm) & $20(15 ; 30)$ \\
\hline \multicolumn{2}{|l|}{ Ulcer location } \\
\hline - Stomach proximal (Fundus/Corpus) & 12 \\
\hline - Stomach distal (Antrum) & 13 \\
\hline - Duodenal Bulb & 25 \\
\hline - Duodenum posterior wall & 30 \\
\hline - Duodenum anterior wall & 17 \\
\hline - Duodenum distal & 3 \\
\hline \multicolumn{2}{|l|}{ Forrestclassification of the lesions } \\
\hline - la (n) & 51 \\
\hline - lb (n) & 23 \\
\hline - Ila (n) & 26 \\
\hline
\end{tabular}

Primary- versus secondary-OTSC

\begin{tabular}{l|l}
\hline - Primary-OTSC (n) & 66 \\
\hline \begin{tabular}{l} 
- Secondary-OTSC (n) \\
\hline Clinical success
\end{tabular} & 34 \\
\hline - Yes & $75(75 \%)$ \\
\hline - No & $25(25 \%)$ \\
\hline
\end{tabular}

Bleeding-related mortality

\begin{tabular}{l|l} 
- Yes & $9(9 \%)$ \\
\hline
\end{tabular}

- No 91

IQR, interquartile range; TTS, through-the-scope clips; OTSC, over the scope clips; ICU, intensive care unit; NSAIDs, nonsteroidal antiinflammatory drugs.

${ }^{1}$ Mean (interquartile range)
PUB with regard to persistent or recurrent bleeding as well as the clinical success of OTSC treatment in the primary and secondary line of treatment.

\section{Patients and methods}

Data for this evaluation were collected prospectively in an endoscopic database (Viewpoint Version 5.6, GE Healthcare $\mathrm{GmbH}$, Solingen Germany). We extracted all information on use of OTSC for PUB. Before and after endoscopic treatment, clinical data for the patient cohort were recorded ( $>$ Table 1 ). Onset of bleeding, patient symptoms, baseline hemoglobin $(\mathrm{g} / \mathrm{L})$, blood-urea-nitrogen (BUN, $\mathrm{mg} / \mathrm{dL}$ ) and lactate $(\mathrm{mmol} / \mathrm{L})$ were documented, if available.

Prior to endoscopy, all patients received an 80 -mg intravenous bolus of pantoprazole. Treatment was continued at a dose of $80 \mathrm{mg}$ daily for at least 72 hours. Blood transfusion was initiated in case of $\mathrm{Hb}$ value $<70 \mathrm{~g} / \mathrm{L}$, hemodynamic instability as well as persistent bleeding. Patients with hemodynamic instability were admitted to the intensive care unit (ICU). Length of ICU stay was also recorded.

The procedures were performed by experienced endoscopists in a 24/7 on-call service. We recorded the numbers of OTSC procedures performed by each endoscopist. To evaluate endoscopist performance relative to his/her experience, three groups were created, depending on the number of clips applied ( 1 - 5 OTSC; 5 - 20 OTSC and > 20 OTSC).

In cases of active bleeding or a visible vessel, the OTSC was applied using a therapeutic endoscope (GIF HQ190, OlympusEurope, Hamburg, Germany). The suction method was used in all cases. All interventions were performed with the $12-\mathrm{mm}$ type-t clip mounted on a 6-mm cap (Ovesco Endoscopy AG, Tübingen, Germany) and were performed under either general anesthesia or midazolam/propofol sedation. Depending on the clinical situation and the endoscopic presentation, one or two clips were placed to control bleeding.

Furthermore, ulcer size (in millimeters), Forrest classification and location (stomach or duodenum) of the target lesion were documented.

Primary OTSC treatment was defined as endoscopic treatment without any prior endoscopic hemostatic approach. Secondary OTSC treatment was defined as rescue OTSC-therapy within 30 days after failed initial endoscopic hemostasis with injection therapy (adrenalin and/or fibrin glue), through-thescope hemoclips (TTS) or a combination of injection and clip therapy ( $\triangleright$ Fig. 1 ).

The primary outcome was defined as successful initial hemostasis with no recurrent bleeding or further surgical, radiological or endoscopic treatment required.

Persistent bleeding was defined as immediate failure of endoscopic treatment proven by ongoing bleeding (oozing or squirting) after endoscopic hemostasis.

Recurrent bleeding was diagnosed if a retreatment of the target lesion was required after initial successful endoscopic treatment. Repeat endoscopy was performed if clinical symptoms of rebleeding occurred (hematemesis or recurrence of 


\begin{tabular}{|c|c|}
\hline \multicolumn{2}{|c|}{ OTSC in $n=100$ patients with PUB } \\
\hline$\sqrt{ }$ & $\downarrow$ \\
\hline Primary OTSC & Secondary OTSC \\
\hline$n=66$ & $n=34$ \\
\hline $\mathrm{F}^{1}$ la 35 (52.3\%) & F la $16(48.6 \%)$ \\
\hline F Ib $12(18.5 \%)$ & F Ib 11 (31.4\%) \\
\hline F Illa 19 (29.2\%) & F Ila 7 (20\%) \\
\hline Persistent bleeding & Persistent bleeding \\
\hline$n=6(9.1 \%)$ & $n=2(5.9 \%)$ \\
\hline$O p^{2} n=2$ & \\
\hline Angio ${ }^{3} n=4$ with & Angio $n=2$ with \\
\hline $\mathrm{n}=2 \mathrm{BRM}^{4}$ palliativ & $\mathrm{n}=1 \mathrm{BRM}$ palliativ \\
\hline$\downarrow$ & $\downarrow$ \\
\hline $\begin{array}{l}\text { Successful hemostasis } \\
\qquad n=60 \text { (90.9\%) }\end{array}$ & $\begin{array}{c}\text { Successful hemostasis } \\
n=32(94.1 \%)\end{array}$ \\
\hline$\downarrow$ & $\downarrow$ \\
\hline Recurrent bleeding & Recurrent bleeding \\
\hline$N=10(16.7 \%)$ & $n=7(21.9 \%)$ \\
\hline $\begin{array}{c}n=3 \text { Early }(<24) \text { vs. } \\
n=7 \text { late }(2-5 d)\end{array}$ & $\begin{array}{c}n=2 \text { early }(<24 h) \text { vs. } \\
n=5 \text { late }(4-12 d)\end{array}$ \\
\hline EndoTx ${ }^{5} n=4$ with & EndoTx $n=2$ \\
\hline BRM palliativ $n=1$ & Angio $n=1$ \\
\hline Angio $n=3$ & EndoTx + Angio $n=3$ \\
\hline EndoTx + Angio $n=1$ & EndoTx + Angio \\
\hline EndoTx + OP = 1 & $+O p n=1$ \\
\hline BRM palliativ $n=1$ & BRM palliativ $n=1$ \\
\hline$\downarrow$ & $\downarrow$ \\
\hline Clinical success & Clinical success \\
\hline $\mathrm{n}=50(75.8 \%)$ & $n=25(73.5 \%)$ \\
\hline
\end{tabular}

- Fig. 1 Flowchart of the OTSC (over-the-scope-clip) treatment in $\mathrm{n}=100$ patients with peptic ulcer bleeding (PUB). Primary-OTSC treatment was when no other endoscopic hemostatic approach had been performed. Secondary-OTSC was a rescue OTSC-therapy after failed initial endoscopic hemostasis with the combination of injection therapy and through-the-scope clips (TTS). Persistent bleeding was when the bleeding source could not be controlled by endoscopic treatment alone. If initial endoscopic OTSC treatment (primary-OTSC or secondary-OTSC) could stop the bleeding, the case was counted as successful hemostasis. Recurrent bleeding was detected by clinical presentation or endoscopy and further therapy initiated. If no other treatment modality was necessary besides the OTSC application, the case was classified as clinical success with OTSC treatment.

${ }^{1} \mathrm{~F}=$ Forrest stage of the ulcer

${ }^{2} \mathrm{OP}=$ operative treament of the bleeding site

${ }^{3}$ Angio = angiographic treatment of the bleeding

${ }^{4} \mathrm{BRM}=$ Bleeding related mortality

${ }^{5}$ EndoTx $=$ Endoscopic therapy

melena) or the patient developed signs of hemodynamic shock (tachycardia or hypotension).

A "second-look endoscopy" was not performed routinely if initial clip placement and hemostasis were deemed successful.
Secondary outcomes were clinical risk factors potentially associated with OTSC failure. We evaluated the location of bleeding onset (new admission versus in-patient bleeding), presence of anticoagulation treatment, use of nonsteroidal anti-inflammatory drugs (NSAIDs), Rockall Score, Glasgow Blatchford Score (GBS), baseline hemoglobin $(\mathrm{g} / \mathrm{L})$, blood urea nitrogen (BUN $\mathrm{mg} / \mathrm{dL}$ ), Lactate $(\mathrm{mmol} / \mathrm{L})$, baseline red blood cell transfusions, ulcer location (stomach versus duodenum), Forrest classification of the lesion as well as ulcer size (cm).

After discharge from the hospital, the patient clinical complexity level (PCCL), reimbursement in Euros, length of time in the intensive care unit (ICU days) and the Case Mix Index (CMI) of the German Diagnosis Related Groups (G-DRG), a measure of the financial investment in each individual case, was evaluated.

Mortality in the patient cohort was also documented. Bleeding-related mortality (BRM) was compared to clinical success of the OTSC treatment. We defined BRM as mortality from either clinical failure or events of rebleeding.

The data were collected and evaluated using Microsoft Excel 2008 for Mac, SPSS for Mac (Version 25.0 Armonk, IBM Corp. New York, United States) and R (Version 3.4.4).

Categorical variables were summarized by absolute percentages and continuous variables by median and 95 interquartile range (IQR).

Differences were evaluated by Fisher's exact or the Pearson's Chi-square test. In quantitative values, differences were measured using the Wilcoxon Rank test.

A $P$ value $<0.05$ was considered statistically significant.

Multivariate logistic regression analysis with a forward stepwise selection strategy using a likelihood ratio, including the report of relative risks and their $95 \% \mathrm{Cls}$, was used to identify independent risk factors for failure of bleeding control.

This study was conducted in accordance with the ethical principles of the Declaration of Helsinki, in compliance with good clinical practice and according to local regulations. All patients gave written informed consent to the endotherapy. The study was not supported financially or otherwise by any external source.

\section{Results}

From April 2014 to March 2018, 100 patients (mean age 76 [20 - 98] years, female $36 \%$, male 64\%) with PUB in the stomach or duodenum were treated endoscopically with the OTSC Clip in the Department of Internal Medicine III at the University Hospital Augsburg, Germany.

\section{Primary vs. secondary OTSC}

The OTSC was used as a first-line procedure (Primary-OTSC) in 66 patients. Initial bleeding control was achieved in $90.9 \%$ ( $\triangleright$ Fig. 1), six of these patients (9.1\%) suffered from persistent bleeding after technically successful OTSC placement in five cases. Subsequent salvage therapy with angiographic obliteration (4 cases) or surgery (2 cases) was performed.

After successful angiographic obliteration, two patients refused further treatment and died in a palliative situation (3.0\%). 
- Table 2 Characteristics of the patients with primary- or secondary-OTSC treatment.

\begin{tabular}{|c|c|c|c|}
\hline & Primary OTSC & Secondary OTSC & $P$ \\
\hline & $n=66$ & $n=34$ & \\
\hline $\mathrm{Age}^{1}$ & $77(67 ; 83)$ & $71(61 ; 81)$ & 0.32 \\
\hline Patient clinical complexity level (PCCL) ${ }^{1}$ & $3(1 ; 4)$ & $3(2 ; 4)$ & 0.88 \\
\hline Gender & & & 1 \\
\hline - male & $42(0.64)$ & $22(0.65)$ & \\
\hline - female & $24(0.36)$ & $12(0.35)$ & \\
\hline Outpatient bleed & $37(0.56)$ & $20(0.59)$ & 0.83 \\
\hline Inpatient bleed & $29(0.44)$ & $14(0.41)$ & \\
\hline Anticoagulation & & & 0.37 \\
\hline - None & $33(0.5)$ & $23(0.68)$ & \\
\hline - ASS mono & $6(0.09)$ & $2(0.06)$ & \\
\hline - NOAK & $7(0.11)$ & $1(0.03)$ & \\
\hline - combinations & $20(0.30)$ & $8(0.24)$ & \\
\hline NSAIDs & & & 0.48 \\
\hline - No & $31(0.74)$ & $18(0.69)$ & \\
\hline - Yes & $9(0.21)$ & $8(0.31)$ & \\
\hline - Unclear & $2(0.05)$ & $0(0)$ & \\
\hline $\operatorname{ICU}(d)^{1}$ & $3(2 ; 5)$ & $4(3 ; 7.25)$ & 0.05 \\
\hline Rockall Score ${ }^{1}$ & $7(6 ; 8)$ & $7(6 ; 8.75)$ & 0.52 \\
\hline Glasgow Blatchford Score (GBS) ${ }^{1}$ & $16(14 ; 17)$ & $15(12.5 ; 16)$ & 0.14 \\
\hline Baseline hemoglobin $(\mathrm{g} / \mathrm{L})^{1}$ & $68(58 ; 76)$ & $66(56.5 ; 73.75)$ & 0.42 \\
\hline BUN $(\mathrm{mg} / \mathrm{dL})^{1}$ & $89.5(66 ; 116)$ & $82.5(49.75 ; 118.5)$ & 0.47 \\
\hline Lactate $(\mathrm{mmol} / \mathrm{l})^{1}$ & $2.5(1.1 ; 4.5)$ & $5.25(2.58 ; 7.18)$ & 0.07 \\
\hline Baseline red cell transfusions ${ }^{1}$ & $3(2 ; 4)$ & $4(3 ; 7)$ & 0.06 \\
\hline Case mix Index ${ }^{1}$ & $2.149(1.16 ; 3.60)$ & $2.37(1.41 ; 3.56)$ & 0.3 \\
\hline Reimbursement (Euro) ${ }^{1}$ & $7217(3874 ; 11985)$ & $7835.5(4597 ; 11836.25)$ & 0.38 \\
\hline Ulcer size $(\mathrm{cm})^{1}$ & $2(1.5 ; 3)$ & $2(1.5 ; 3)$ & 0.61 \\
\hline Location of the ulcer & & & 1 \\
\hline stomach & $17(0.26)$ & $8(0.24)$ & \\
\hline duodenum & $49(0.74)$ & $26(0.77)$ & \\
\hline Forrest & & & 0.26 \\
\hline la (n; rel. \%) & $35(0.53)$ & $16(0.47)$ & \\
\hline $\mathrm{Ib}$ & $12(0.18)$ & $11(0.32)$ & \\
\hline Ila & $19(0.29)$ & $7(0.21)$ & \\
\hline Technical success & & & 1 \\
\hline yes (rel. \%) & 65 (0.99) & $34(1)$ & \\
\hline no & $1(0.015)$ & $0(0)$ & \\
\hline Clinical success & & & 0.81 \\
\hline yes (rel. \%) & $50(0.76)$ & $25(0.74)$ & \\
\hline no & $16(0.24)$ & $9(0.27)$ & \\
\hline
\end{tabular}


- Table 2 (Continuation)

\begin{tabular}{|l|l|l|}
\hline & Primary OTSC & Secondary OTSC \\
\hline $\begin{array}{l}\text { Experience Physician } \\
\text { OTSC/endoscopist }\end{array}$ & $\mathbf{n = 6 6}$ & $\mathbf{n = 3 4}$ \\
\hline$<5$ & $19(0.29)$ & $3(0.09)$ \\
\hline $5-20$ & $5(0.08)$ & $8(0.24)$ \\
\hline$>20$ & $42(0.64)$ & $23(0.68)$ \\
\hline Bleeding-related mortality & & \\
\hline Yes & $6(0.09)$ & $3(0.09)$ \\
\hline No & $60(0.91)$ & $31(0.91)$ \\
\hline $\begin{array}{l}\text { IQR, interquartile range; TTS, through-the-scope clips; OTSC, over-the-scope clips; ICU, intensive care unit; NSAIDs, nonsteroidal antiinflammatory drugs. } \\
1 \text { Mean (interquartile range) }\end{array}$ & \\
\hline
\end{tabular}

The OTSC was used as a second-line procedure (secondaryOTSC) for reactivated bleeding after successful initial endoscopic hemostasis with injection of adrenalin (mean $15 \mathrm{~mL}$ range: $5-50 \mathrm{~mL}$ ) or fibrin glue (mean $2 \mathrm{~mL}$ range: $1-4 \mathrm{~mL}$ ). For mechanical bleeding control, only treatment with TTS (mean 4 range $1-12$ ) was allowed in this study. In this group the bleeding source showed active bleeding (Forrest la or lb) in $n=27$ cases. In seven cases a non-bleeding visible vessel was found (Forrest Ila). Two patients suffered from persistent bleeding (5.9\%) after OTSC treatment. Both patients underwent angiographic obliteration of the feeding vessel. One patient refused further treatment and died in palliative care (2.9\%).

Successful hemostasis with secondary-OTSC was achieved in $94.1 \%$. Persistent bleeding after OTSC treatment occurred in $8 \%$ of all cases (primary- and secondary-OTSC).

Recurrent bleeding occurred 1 to 12 days after successful initial treatment, (median $3.5 \mathrm{~d})$ in $16.7 \%(\mathrm{~N}=10)$ after primaryOTSC and $21.9 \%(\mathrm{~N}=7)$ after secondary-OTSC treatment $(P=$ $0.81)$.

In the primary-OTSC group, ten patients (16.7\%) suffered an early recurrent bleeding ( $<24$ hours, $n=3$ ) or had late recurrent bleeding ( $>24$ hours range $2-5$ days, $n=7$ ). In four patients, a second endoscopic treatment was successful but one patient died in a palliative situation after successful bleeding control. Four patients received angiography and one surgery for bleeding control. One patient developed symptoms of recurrent bleeding but a reintervention was denied because of comorbidities and the patient's age (90 years).

In the secondary-OTSC group, seven patients (21.2\%) developed early rebleeding $(<24$ hours, $n=2)$ or late rebleeding (> 24 hours range 4-12 days, $n=5$ ). Successful endoscopic treatment was achieved in two patients and five patients were treated with angiographic obliteration. One patient underwent surgery ( Fig. 1).

Recurrent bleeding occurred in $17 \%$ of all cases (primaryand secondary-OTSC).
The overall clinical success for OTSC in the primary-OTSC group was $75.8 \%$ versus $73.5 \%$ in the secondary-OTSC group $(P=0,81)$ ( $\triangleright$ Fig. 1 and $\triangleright$ Table 1$)$.

\section{Factors associated with OTSC failure}

In the group of patients with persistent or recurrent bleeding we found no differences in risk stratification scores (Rockall and Glasgow Blatchford Socre), baseline hemoglobin, BUN or lactate. Also, no differences in the frequency of antiplatelet or anticoagulant drugs or NSAID use. There were no differences between new admission- or inpatient bleeders ( $>$ Table 2 ).

The mean amount of packed red blood cells transfused in the OTSC failure group was higher ( 4 versus $3, P=0,01$ ) and ulcer size was larger (30 versus $20 \mathrm{~mm}, P=0.07$ ).

Duration of ICU treatment was longer ( 4 versus 3 days, $P=$ 0.02 ). Reimbursement per case for the treatment failure group was higher from those successfully treated with OTSC (10055 Euro versus 6155 Euro $P=0.04$ ) (CMI 3.036 versus $1.892 P=$ 0.04 ). The trend showed a higher reimbursement and $C M I$ in case of treatment escalation with operation or angiographic intervention.

The proportion of active oozing (Forrest lb $23 \%$ ) or spurting (Forrest la $51 \%$ ) bleeding ulcers was $74 \%$ ( $>$ Fig. 1, \ Fig. 2) in the entire study cohort. A visible vessel (Forrest Ila) was found in $26 \%$ of ulcers ( $\triangleright$ Fig. 3 ). We found a slightly higher rate of ulcers with a visible vessel (Forrest Ila) in the primary-OTSC group (29.2\% vs. $20.6 \% P=0,26)$.

Treatment success was independent of Forrest stage of the ulcer $(P=0.26)$.

Endoscopic treatment was performed by 15 different physicians in our institution. To evaluate the grade of experience with the OTSC system in an active bleeding situation, we analyzed three groups: fewer than 5 OTSC applications, five to 20 or more than 20 clip applications ( $>$ Table 3 ). We found no difference in the bleeding control rate among the groups $(P=0,58)$. Interestingly, we had a higher rate of OTSC-unexperienced physicians ( $<5$ OTSC) in the primary-OTSC group $(28.8 \%)$ than in the middle group $(5-20) 7.6 \%(P=0.02)$. The 


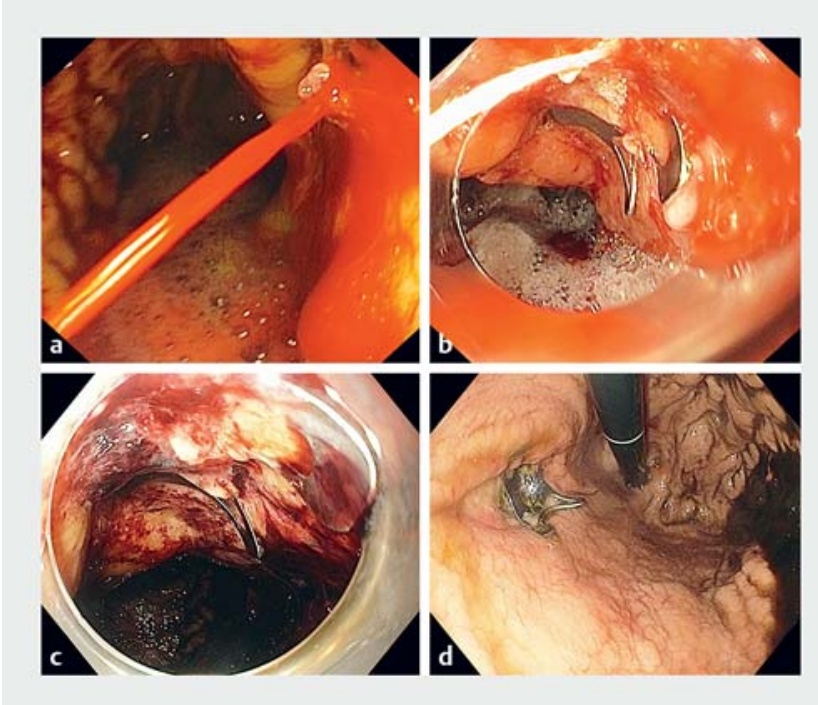

- Fig. 2 Primary-OTSC. a Forrest la bleeding in the stomach diagnosed during emergency endoscopy. $\mathbf{b}$ An OTSC mounted on the therapeutic endoscope was successfully placed on the bleeding site. c, d After initial bleeding control and in the control endoscopy after 3 days, the clip was found in position.

most experienced physicians had comparable applications in the primary- or secondary-OTSC group (63.6\% versus $67.7 \%$ ). Logistic regression for clinical failure identified ulcer size and location in the duodenum, especially at the posterior duodenal wall, as factors associated with a higher rate of treatment failure ( $\triangleright$ Table 4). Also, the transfusion requirement was higher in the treatment failure group.

\section{Bleeding-related mortality}

The rate of BRM was $6 \%$ (6 patients). In case of failure of clinically successful OTSC treatment $(n=3)$, all patients received angiographic bleeding control, but died due to prolonged hemorrhagic shock.

In case of recurrent bleeding, the bleeding source could be controlled by endoscopic treatment but the patient denied any further therapy.

Three patients (3\%) in the successful hemostasis group also died due to prolonged hemorrhagic shock but showed no symptoms of recurrent bleeding and were also classified as BRM.

Seven patients $(7 \%)$ died for reasons other than intestinal bleeding (sepsis $5 \times$, decompensated liver cirrhosis, cardiorespiratory failure).

BRM occurred more often in the uncontrolled bleeding group ( 3 vs. 6 patients $P=0.007$ ), but we found no difference between the primary-OTSC versus secondary OTSC group (6\% in both groups, > Fig. 1, > Table 1, > Table 2).

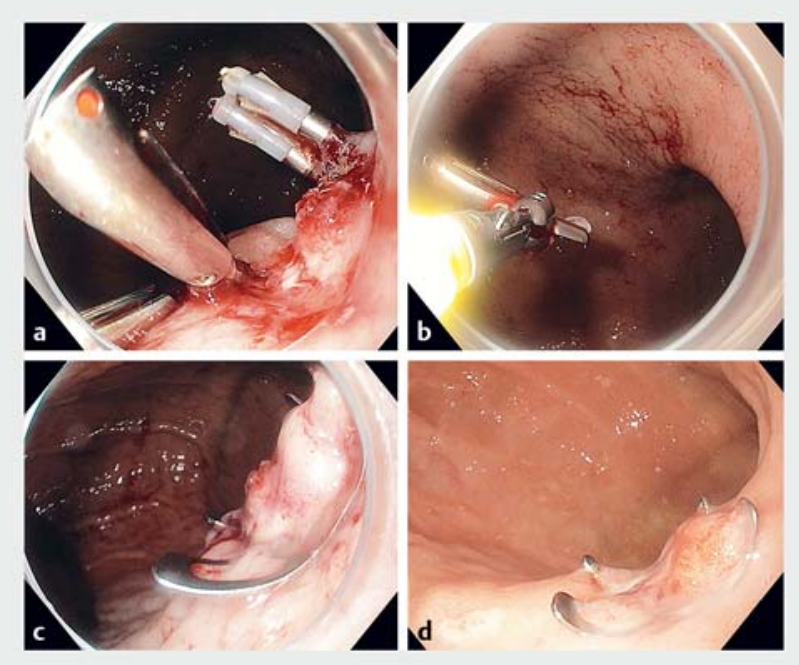

- Fig. 3 Secondary-OTSC. a Large ulcer with a central vessel. Prior to examination, TTS clips had been placed. $\mathbf{b}$ Because of recurrent bleeding, the TTS clips were removed. c An OTSC was placed on the central vessel. $\mathbf{d}$ In the second-look endoscopy the vessel was successfully closed by the OTSC.

\section{Discussion}

Our study shows that the primary-OTSC for first-line treatment of PUB has a comparably high rate of initial bleeding control with secondary-OTSC (90.9\% versus $94.1 \%)$. Nevertheless, in the primary-OTSC group, we found a higher rate of salvage therapy (angiographic or surgery) of $9.1 \%$ compared to $5.9 \%$ in the secondary-OTSC group. This in part could be due to the fact that we had a per group higher rate of Forrest la (spurting) bleedings $53 \%$ versus $47 \%(P=0.26)$ in the secondary-OTSC group. Forrest la ulcers have a higher per lesion rate of persistent and recurrent bleeding [9].

After successful initial treatment with the OTSC, recurrent bleeding occurred more often in the secondary-OTSC group than in the primary-OTSC group ( $21.9 \%$ vs $16.7 \%)$. This could be explained by the efficiency of the OTSC clip itself. This device has a higher compression force and therefore, obliteration of the feeding vessel is higher than with conventional TTS Clips. We also found more visible vessels (Forrest Ila) in the primaryOTSC (29.2\%) compared to the secondary-OTSC group (20\%) $(P=0.26)$. In the secondary-OTSC we might have a selection of more difficult-to-treat bleeding lesions. Therefore, a higher rate of recurrence may be explained. We also found that two recurrent bleeds occurred 8 and 12 days after the initial OTSC treatment. In one patient the clip was still in position and in one patient the clip had dislodged completely from the ulcer.

In the first prospective randomized trial comparing the OTSC as second-line therapy with conventional endoscopic retreatment, Schmidt et al. found $6.1 \%$ rate of persistent bleeding and a $9.1 \%$ rate of recurrent bleeding compared to $42.2 \%$ persistent bleeding and $16.1 \%$ recurrent bleeding for conventional endoscopic treatment. This defined the OTSC as the new stand- 
- Table 3 Factors associated with clinical failure in OTSC treatment for peptic ulcer bleeding.

\begin{tabular}{|c|c|c|c|}
\hline & \multicolumn{2}{|c|}{ Clinical success with OTSC treatment } & \multirow[b]{2}{*}{$P$} \\
\hline & Yes $n=75$ & No $n=25$ & \\
\hline Age $^{1}$ & $76(62.5 ; 83)$ & $72(65 ; 83)$ & 0.96 \\
\hline Patient Clinical Complexity Level (PCCL) ${ }^{1}$ & $3(1 ; 4)$ & $4(2 ; 4)$ & 0.08 \\
\hline Gender & & & 0.16 \\
\hline - male & $51(0.68)$ & $13(0.52)$ & \\
\hline - female & $24(0.32)$ & $12(0.48)$ & \\
\hline Outpatient bleed & $42(0.56)$ & $15(0.6)$ & 0.82 \\
\hline Inpatient bleed & $33(0.44)$ & $10(0.4)$ & \\
\hline Anticoagulation & & & 0.34 \\
\hline - None & $40(0.53)$ & $16(0.64)$ & \\
\hline - ASS mono & $8(0.11)$ & $0(0)$ & \\
\hline - NOAC & $7(0.09)$ & $1(0.04)$ & \\
\hline - others (Combination) & $20(0.27)$ & $8(0.32)$ & \\
\hline NSAIDs & & & 0.76 \\
\hline - No & $36(0.735)$ & $13(0.684)$ & \\
\hline - Yes & $12(0.245)$ & $5(0.263)$ & \\
\hline - Unclear & $1(0.02)$ & $1(0.053)$ & \\
\hline $\operatorname{ICU}(\mathrm{d})^{1}$ & $3(2 ; 6)$ & $4(3 ; 9)$ & 0.02 \\
\hline Rockall Score $^{1}$ & $7(6 ; 8)$ & $8(6 ; 9)$ & 0.15 \\
\hline Glasgow Blatchford Score (GBS) ${ }^{1}$ & $15(14 ; 17)$ & $16(15 ; 18)$ & 0.10 \\
\hline Baseline hemoglobin $(\mathrm{g} / \mathrm{L})^{1}$ & $67(57 ; 74.5)$ & $70(58 ; 75)$ & 0.51 \\
\hline BUN $(\mathrm{mg} / \mathrm{dL})^{1}$ & $87(57 ; 118)$ & $92(75 ; 116)$ & 0.44 \\
\hline Lactate $(\mathrm{mmol} / \mathrm{l})^{1}$ & $2.6(1.38 ; 6.8)$ & $4.1(2.582 ; 8.5)$ & 0.23 \\
\hline Baseline red cell transfusions ${ }^{1}$ & $3(2 ; 4)$ & $4(3 ; 9)$ & 0.01 \\
\hline Case mix Index ${ }^{1}$ & $1.892(1.19 ; 3.37)$ & $3.036(1.804 ; 4.683)$ & 0.04 \\
\hline Reimbursement (Euro) ${ }^{1}$ & $6155(3904.5 ; 11125)$ & $10055(6044 ; 15690)$ & 0.04 \\
\hline Ulcer size $(\mathrm{cm})^{1}$ & $2(1 ; 3)$ & $3(2 ; 3)$ & 0.07 \\
\hline \multicolumn{4}{|l|}{ Location of the ulcer } \\
\hline - Stomach proximal (Fundus/Corpus) & $10(0.13)$ & $2(0.08)$ & 0.05 \\
\hline - Stomach distal (Antrum) & $13(0.17)$ & $0(0)$ & \\
\hline - Duodenal bulb & $19(0.25)$ & $6(0.24)$ & \\
\hline Duodenum posterior wall & $17(0.23)$ & $13(0.52)$ & \\
\hline - Duodenum anterior wall & $13(0.17)$ & $4(0.16)$ & \\
\hline - Duodenum distal & $3(0.04)$ & $0(0)$ & \\
\hline Forrest & & & 0.26 \\
\hline - la & $35(0.47)$ & $16(0.64)$ & \\
\hline - Ib & $20(0.27)$ & $3(0.12)$ & \\
\hline - Ila & $20(0.27)$ & $6(0.24)$ & \\
\hline
\end{tabular}


- Table 3 (Continuation)

\begin{tabular}{|c|c|c|c|}
\hline & \multicolumn{2}{|c|}{ Clinical success with OTSC treatment } & \multirow[b]{2}{*}{$P$} \\
\hline & Yes $n=75$ & No $n=25$ & \\
\hline Primary vs. Secondary OTSC & & & 0.81 \\
\hline - Primary OTSC & $50(0.67)$ & $16(0.64)$ & \\
\hline - Secondary OTSC & $25(0.33)$ & $9(0.36)$ & \\
\hline Primary treatment $(\mathrm{w} / \mathrm{o})$ OTSC & & & 0.28 \\
\hline - Adrenalin +TTS & $8(0.33)$ & $5(0.46)$ & \\
\hline - Adrenalin +TTS + Fibrin Clue & $13(0.54)$ & $3(0.27)$ & \\
\hline - Fibrin Clue & $3(0.13)$ & $2(0.18)$ & \\
\hline - OTSC in recurrent Primary-OTSC & $0(0)$ & $1(0.09)$ & \\
\hline Frequency of OTSC Applications/doctor & & & 0.58 \\
\hline$\cdot<5$ & $15(0.2)$ & $7(0.28)$ & \\
\hline - $5-20$ & $11(0.15)$ & $2(0.08)$ & \\
\hline.$>20$ & $49(0.65)$ & $16(0.64)$ & \\
\hline
\end{tabular}

- Table 4 Logistic regression for factors associated with clinical failure in OTSC treatment for peptic ulcer bleeding.

\begin{tabular}{|c|c|c|}
\hline Factors & OR $(\mathrm{Cl})$ & $P$ value \\
\hline $\operatorname{ICU}(\mathrm{d})$ & $1.04(0.97-1.12)$ & 0.30 \\
\hline Baseline red cell transfusion & $1.31(1.13-1.57)$ & 0.01 \\
\hline Stomach vs. duodenum & $4.96(1.30-32.74)$ & 0.04 \\
\hline Duodenum posterior wall & $8.11(1.89-56.94)$ & 0.01 \\
\hline Ulcer size ( $\geq 1.5 \mathrm{~cm}$ ) & $7.19(1.31-134.49)$ & 0.07 \\
\hline Anticoagulation & $0.64(0.23-1.79)$ & 0.40 \\
\hline
\end{tabular}

ard in endoscopic treatment for recurrent peptic ulcer bleeding.

The clinical success rate of primary- and secondary-OTSC in our study is almost comparable (75.8\% vs. $73.5 \%$ ).

The clinical success rate of the first prospective randomized trial by Schmidt et al. found a final success rate of $84.8 \%$ for second-line treatment in PUB. In this study, the rate of Forrest la bleeding was $16.7 \%$ in a follow-up period of 30 days after initial bleeding control. Other case series or retrospective studies found rates of initial bleeding control of $77 \%$ to $100 \%$ and of rebleeding of $7 \%$ to $42.8 \%$ [10-21].

We evaluated factors that might influence the clinical success of endoscopic treatment in PUB [22]. We found that ulcer location in the duodenum resulted in a higher rate of unsuccessful OTSC treatment. Ulcer size in the treatment failure group was larger ( 3 vs. $2 \mathrm{~cm}$ ) but this did not reach statistical significance. In logistic regression we found that ulcer location at the posterior duodenal wall was a factor associated with OTSC failure $(P=0.01)$. This finding is in accord with the current literature that could show a higher treatment failure for ulcers in this location [22, 23].

As a consequence of the more severe clinical scenario of failed endoscopic hemostasis, we found a longer ICU stay and a higher rate of red blood cell transfusions.

According to the German reimbursement system (G-DRG), the case mix index (CMI) and the reimbursement rate were higher for uncontrolled bleeding. There is only limited data on the reimbursement rate and cost of failed hemostasis in gastroduodenal ulcer bleeding. A study from the United States found higher cost as well as reimbursement in case of salvage therapy with angiography or surgery [24].

Also of interest is the finding that we could not identify a difference in the experience of the endoscopist who applied the OTSC clip. This is comparable to other studies that showed a high rate of bleeding control when the OTSC system was used as the initial treatment modality. But our work is the first to show this in a real-life setting in a large referral endoscopy unit with 15 different endoscopists performing the procedure.

We found an overall mortality rate of $16 \%$ in our cohort. Seven patients died of reasons unrelated to bleeding and in three patients, bleeding was controlled but the patients died of prolonged hemorrhagic shock. Six patients died due to recurrent bleeding from the initial source. The overall rate of mortality was comparable to published data in severe ulcer bleeding and OTSC treatment of $10 \%$ to $18 \%[8,12,21]$.

There are some limitations to our findings. This is a retrospective evaluation of prospectively collected data, which did not compare OTSC treatment to conventional endoscopic hemostasis. Patient recruitment was performed within a time period of 4 years. Patient allocation to a treatment arm was 
based on the character of the bleeding (initial versus recurrent bleeding) which could be a source of potential bias.

Recent studies show that endoscopic doppler examination of the ulcer base could direct the endoscopic therapy, this was not performed during our study $[25,26]$.

\section{Conclusion}

In conclusion, the OTSC has a high rate of initial bleeding control in first- and second line treatment for PUB. The rate of recurrent bleeding was lower in first- than in second-line treatment in our study. Location of the bleeding source and ulcer size may influence the success of treatment.

\section{Competing interests}

None

\section{References}

[1] van Leerdam ME. Epidemiology of acute upper gastrointestinal bleeding. BestPractRes Clin Gastroenterol 2008; 22: 209-224

[2] Hearnshaw SA, Logan RF, Lowe D et al. Acute upper gastrointestinal bleeding in the UK: patient characteristics, diagnoses and outcomes in the 2007 UK audit. Gut 2011; 60: 1327-1335

[3] Laine L, Yang H, Chang SC et al. Trends for incidence of hospitalization and death due to $\mathrm{Gl}$ complications in the United States from 2001 to 2009. Am J Gastroenterol 2012; 107: 1190 - 1195; quiz 1196

[4] Gralnek IM, Dumonceau JM, Kuipers EJ et al. Diagnosis and management of nonvariceal upper gastrointestinal hemorrhage: European Society of Gastrointestinal Endoscopy (ESGE) Guideline. Endoscopy 2015; 47: a1 - 46

[5] Barkun AN, Bardou M, Kuipers E] et al. International consensus recommendations on the management of patients with nonvariceal upper gastrointestinal bleeding. Ann Intern Med 2010; 152: 101 - 113

[6] Götz M, Anders M, Biecker E et al. [S2k Guideline Gastrointestinal Bleeding - Guideline of the German Society of Gastroenterology DGVS]. Z Gastroenterol 2017; 55: 883-936

[7] van Leerdam ME, Vreeburg EM, Rauws EAJ et al. Acute upper GI bleeding: did anything change? Time trend analysis of incidence and outcome of acute upper Gl bleeding between 1993/1994 and 2000 Am J Gastroenterol 2003; 98: 1494-1499

[8] Schmidt A, Gölder S, Goetz M et al. Over-the-scope clips are more effective than standard endoscopic therapy for patients with recurrent bleeding of peptic ulcers. Gastroenterology 2018; 155: 674-686. e676

[9] Laine L, Peterson WL. Bleeding peptic ulcer. N Engl J Med 1994; 331: $717-727$

[10] Albert JG, Friedrich-Rust M, Woeste G et al. Benefit of a clipping device in use in intestinal bleeding and intestinal leakage. Gastrointest Endosc 2011; 74: 389-397
[11] Baron TH, Song LM, Ross A et al. Use of an over-the-scope clipping device: multicenter retrospective results of the first U.S. experience (with videos). Gastrointest Endosc 2012; 76: 202-208

[12] Brandler J, Baruah A, Zeb M et al. Efficacy of over-the-scope clips in management of high-risk gastrointestinal bleeding. Clin Gastroenterol Hepatol 2017; 16: 690-696

[13] Chan SM, Chiu PW, Teoh AY et al. Use of the over-the-scope clip for treatment of refractory upper gastrointestinal bleeding: a case series. Endoscopy 2014; 46: 428-431

[14] Kirschniak A, Subotova N, Zieker D et al. The over-the-scope clip (OTSC) for the treatment of gastrointestinal bleeding, perforations, and fistulas. Surg Endosc 2011; 25: $2901-2905$

[15] Manno M, Mangiafico S, Caruso A et al. First-line endoscopic treatment with OTSC in patients with high-risk non-variceal upper gastrointestinal bleeding: preliminary experience in 40 cases. Surg Endosc 2016; 30: 2026-2029

[16] Manta R, Galloro G, Mangiavillano B et al. Over-the-scope clip (OTSC) represents an effective endoscopic treatment for acute GI bleeding after failure of conventional techniques. Surg Endosc 2013; 27: $3162-3164$

[17] Monkemuller K, Peter S, Toshniwal J et al. Multipurpose use of the 'bear claw' (over-the-scope-clip system) to treat endoluminal gastrointestinal disorders. Dig Endosc 2014; 26: 350 - 357

[18] Nishiyama N, Mori H, Kobara $\mathrm{H}$ et al. Efficacy and safety of over-thescope clip: including complications after endoscopic submucosal dissection. World J Gastroenterol 2013; 19: $2752-2760$

[19] Richter-Schrag H], Glatz T, Walker C et al. First-line endoscopic treatment with over-the-scope clips significantly improves the primary failure and rebleeding rates in high-risk gastrointestinal bleeding: A single-center experience with 100 cases. World J Gastroenterol 2016; 22: $9162-9171$

[20] Skinner M, Gutierrez JP, Neumann H et al. Over-the-scope clip placement is effective rescue therapy for severe acute upper gastrointestinal bleeding. Endosc Int Open 2014; 2: E37-E40

[21] Wedi E, Gonzalez S, Menke D et al. One hundred and one over-thescope-clip applications for severe gastrointestinal bleeding, leaks and fistulas. World J Gastroenterol 2016; 22: $1844-1853$

[22] Ogasawara N, Mizuno M, Masui R et al. Predictive factors for intractability to endoscopic hemostasis in the treatment of bleeding gastroduodenal peptic ulcers in Japanese patients. Clin Endosc 2014; 47: $162-173$

[23] Elmunzer B], Young SD, Inadomi JM et al. Systematic review of the predictors of recurrent hemorrhage after endoscopic hemostatic therapy for bleeding peptic ulcers. Am J Gastroenterol 2008; 103: $2625-2632$

[24] Roy A, Kim M, Hawes R et al. The clinical and cost implications of failed endoscopic hemostasis in gastroduodenal ulcer bleeding. United European Gastroenterol J 2017; 5: 359-364

[25] Jensen DM, Kovacs TOG, Ohning GV et al. Doppler endoscopic probe monitoring of blood flow improves risk stratification and outcomes of patients with severe nonvariceal upper gastrointestinal hemorrhage. Gastroenterology 2017; 152: 1310 - 1318 e1311

[26] Jensen DM, Ohning GV, Kovacs TO et al. Doppler endoscopic probe as a guide to risk stratification and definitive hemostasis of peptic ulcer bleeding. Gastrointest Endosc 2016; 83: 129-136 